\title{
Estudantes estrangeiros no Brasil: informação e processos de produção de diferença
}

\author{
Rubens da Silva Ferreira ${ }^{I}$ \\ http://orcid.org/0000-0002-2739-1182 \\ I Universidade Federal do Pará, PA, Brasil. \\ Doutor em Ciência da Informação.Docente e pesquisador \\ do Instituto de Ciências Sociais Aplicadas da UFPA
}

http://dx.doi.org/10.1590/1981-5344/3369

O trabalho adota a tese de que a migração é também processo de circulação de informação, conhecimento e diferença. Neste sentido, investiga-se uma realidade bem específica no amplo panorama da mobilidade humana: os deslocamentos internacionais de estudantes para o Brasil. Sustentado pelas teorizações em torno da produção de diferença e da autonomia das migrações, os estudantes estrangeiros são analisados como migrantes. Os dados qualitativos submetidos à Análise de Conteúdo foram recolhidos entre trinta e cinco estudantes estrangeiros provenientes de países africanos, sul-americanos, caribenhos e europeus. Como resultado, verifica-se um processo que envolve trocas informacionais, cognitivas e culturais que se mesclam em uma experiência migratória que afeta os modos de ser, pensar, sentir e agir dos estudantes migrantes, permitindo que se tornem pessoas diferentes. E em que pesem as dificuldades vividas em terras brasileiras, essa experiência é percebida pelos 
colaboradores da pesquisa como bastante positiva ao final da diplomação/titulação.

Palavras-chave: Migrações; Estudantes estrangeiros; Educação superior;Produção de diferença.

\section{The foreign students in Brazil: information and production of difference}

The work adopts the thesis that migration is also a process of production of information, knowledge and difference. In this sense, a very specific reality is investigated in the broad panorama of human mobility: the international student movements to Brazil. Sustained by theorizations around the production of difference and the autonomy of migration, foreign students are analyzed as migrants. Qualitative data submitted to Content Analysis were collected from thirty-five foreign students from African, South American, Caribbean and European countries. As a result, there is a process that involves informational, cognitive and cultural exchanges that blend into a migratory experience that affects migrant students' ways of being, thinking, feeling and acting, allowing them to become different people. And in spite of the difficulties experienced in Brazilian lands, this experience is perceived by the research collaborators as quite positive at the end of the diploma/degree.

Keywords: Migrations. Foreign students. Higher education. Production of difference.

Recebido em 11.12.2017 Aceito em 11.08.2020 


\section{Introdução}

Como as migrações afetam e transformam a bagagem infocognitiva de quem as vivencia, precisamente nas situações de contato mais intenso com a sociedade de recepção, tal como ocorre com migrantes e outras categorias de pessoas que se lançam à experiência de vida no exterior? É em torno dessa questão que se concentra o esforço de produzir pistas em direção à compreensão do fenômeno migratório contemporâneo, advogando a tese de que as migrações de pessoas são processos de circulação de informação, de conhecimento e de diferença. Melhor dizendo: quem migra leva consigo informações e conhecimentos que são ampliados pelo contato com os modos de ser, pensar, agir e viver na sociedade de recepção, resultando em novas informações e conhecimentos que modificam a bagagem infocognitiva dos migrantes, produzindo, assim, diferença.

$\mathrm{Na}$ vida cotidiana ou na literatura, os deslocamentos representados pelas viagens já aparecem como processos de mudança experimentados por pessoas. Diz-se, neste sentido, que viajar envolve aprendizados diversos, contatos com outras informações e conhecimentos, seja sobre os lugares visitados, sobre os moradores locais ou sobre o próprio viajante, que tem suas subjetividades transformadas enquanto se desloca no espaço físico, experimentando a cultura do outro, a alteridade. Todavia, por representar uma estadia mais prolongada em outra cidade, país ou região, a viagem empreendida pelos migrantes implica estranhamento, adaptação, convívio e maior interação no tempo e no espaço com a sociedade de recepção, então potencializando processos de diferenciação.

No poema homérico Odisseia, apenas para fazer referência a uma antiga narrativa sobre processos de diferença, tem-se a jornada de Ulisses (Odysseús/Ulíkses/Ulixes). Após deixar a família para participar da Guerra de Tróia, o herói passou longos vinte anos percorrendo terra e mar até retornar à terra natal, a ilha de Ítaca. Brandão (2015, p. 134), a respeito, explica que a longa viagem de Ulisses é, em si, uma história sobre o "regresso do esposo ao lar", envolvendo nostalgia e paz, essa última representando uma espécie de "premiação" pelas dificuldades enfrentadas durante os anos de ausência da terra de origem.

Do senso comum e da narrativa grega para experiências concretas, em que ocorrem processos de mudança decorrentes das viagens, este artigo tem como objetivo analisar a experiência de estudantes estrangeiros no Brasil. A base teórica da discussão apoia-se nas contribuições de Bateson (2000) e de Anderson (2008) sobre a noção de produção de diferença, bem como nas teorizações de Mezzadra (2005, 2012) sobre a autonomia das migrações. A base empírica, por sua vez, resulta de material fornecido por 35 estudantes estrangeiros, precisamente por meio de entrevistas e questionário online. Do total de 
pessoas contatadas, 18 são do sexo masculino e 17 do sexo feminino, com idades que variam de 20 a 41 anos de idade, constituindo, assim, um grupo de pessoas classificado como adultos jovens.

Os estudantes em foco são originários de países africanos (Angola; Benin; Cabo Verde; Gana; Guiné-Bissau; Moçambique; República Democrática do Congo; São Tomé e Príncipe; Togo), sul-americanos (Argentina; Chile; Colômbia; Peru; Uruguai; Venezuela), europeus (França e Itália), caribenho (Haiti) eda América Central (Costa Rica). Quando contatados eles se encontravam frequentando cursos de graduação ou de pós-graduação em universidades de diferentes cidades brasileiras, a saber: Ananindeua (Pará); Belém (Pará); Brasília (Distrito Federal); Juiz de Fora (Minas Gerais); Macaé (Rio de Janeiro); Maceió (Alagoas); Natal (Rio Grande do Norte); Recife (Pernambuco); Rio de Janeiro (Rio de Janeiro); São Paulo (São Paulo); e Três Rios (Rio de Janeiro).

Possivelmente alguns deles prosseguem com seus estudos enquanto este trabalho está sendo socializado. Assim, antes de tratar do material empírico submetido à Análise de Conteúdo, importa esclarecer sobre o que se entende quanto à noção de produção e diferença, bem como o sentido em que o termo migrante será utilizado ao longo do texto.

\section{Sobre produção de diferença e autonomia das migrações: breves esclarecimentos}

0 interesse de pesquisar estudantes estrangeiros surgiu com base nas autorreflexões do autor sobre uma experiência vivida em 2008. Àquela época, como estudante em Madri, experimentou-se um processo intenso de troca de informações e conhecimentos sobre a preservação do patrimônio documental, lá compartilhando também o conhecimento levado sobre a realidade brasileira. O convívio diário com estudantes argentinos, bolivianos, costa-riquenhos, cubanos, equatorianos, guatemaltecos, guinéu-equatorianos, paraguaios, peruanos, uruguaios e venezuelanos, assim como o contato com pessoas locais permitiu o compartilhamento de costumes, hábitos e de um saber prático que resultou em um processo de produção de diferença não somente no autor, como também nas pessoas das relações mais imediatas. No dia a dia, essas interações envolveram um aprendizado espontâneo e informal sobre os países e as culturas que ali se encontravam representados pelos estudantes, permitindo que também pudessem conhecer um pouco sobre o Brasil e os brasileiros, inclusive quanto ao que Rezende (2009) observa como o modo afetivo pelo qual esse último grupo costuma ser representado aos olhos do estrangeiro.

Por ocasião do doutoramento em Ciência da Informação, na Universidade Federal do Rio de Janeiro (UFRJ), em 2015 ocorreu o contato 
com a noção de produção de diferença e com a abordagem da autonomia das migrações.

A noção de produção de diferença aqui se fundamenta em Gregory Bateson (2000) e Benedict Anderson (2008). Enquanto Anderson auxilia na compreensão do papel das viagens e da educação no exterior modificando as subjetividades, os modos de pensar e de agir dos colonos enviados às metrópoles para a formação de um corpo burocrático qualificado, Bateson concebe a informação como um estímulo recebido do meio que, sensorialmente percebido como novidade, acaba por produzir algum tipo de diferença nas pessoas.

Em Comunidades imaginadas, Anderson (2008) estimula a pensar a produção de diferença nos domínios da educação, notadamente pelos encontros nas escolas e nas universidades que ocorriam entre os nascidos nas colônias, os indígenas letrados e os metropolitanos. Então, fala-se aqui de uma "intercambialidade" de jovens estudantes, tanto no sentido colônia/metrópole quanto o inverso, muito embora o primeiro fosse mais frequente e procurado, precipuamente quanto à busca por formação em cursos superiores. Desse convívio, que era também linguístico e plural, o contato com novas informações, novos conhecimentos e com os livros que deveriam ler ao longo da formação - ou fora dela - ampliava-se com as trocas culturais, isto é, com o compartilhamento de saberes ligados aos seus locais de origem, modos de vida, formas de pensar e costumes. Uma experiência que, no século XVIII, contribuía para o surgimento dos homines novi, dos funcionários talentosos que serviriam à burocracia metropolitana em função dos conhecimentos e das habilidades que possuíam.

Para Bateson (2000), a informação é a própria diferença que faz diferença. Com base nos estudos dedicados ao campo da comunicação humana, em que procurou compreender como as pessoas produzem ideias e se inter-relacionam a partir delas, o autor propôs uma definição de informação inspirada em sua Teoria do duplo vínculo (double bind). Por meio dela, Bateson (2000) entende que as pessoas estão em processos contínuos de mudança, notadamente pelas informações com quais entram em contato em suas interações comunicativas. Isto as leva a modificarem continuamente sua bagagem infocognitiva, conforme estratégias adaptativas inerentes aos seres vivos, que, para ele, são dotados de deutoaprendizagem: a capacidade de aprender a aprender. Uma capacidade pela qual modificam suas ideias, desejos, comportamentos, hábitos, crenças e valores à medida que assimilam novas informações e conhecimentos.

Teorizações acerca da informação induzindo processos de diferenciação aparecem também em duas importantes referências, sendo uma dela no campo da Sociologia e outra no campo da Ciência da 
Informação. No ensaio A metrópole na vida mental, Simmel (1973) já se ocupava de analisar os efeitos da vida urbana na mente de quem migra do campo para a cidade. A exposição ao excesso de estímulos sonoros e visuais recebidos do meio (informação) afetava os modos de agir, pensar e ser das pessoas, distanciando-as do seu antigo estilo de vida. Concluía Simmel, então, que o homem é um ser que resulta da diferenciação.

Em outro trabalho, Information Science and the phenomenon of information, escrito por Belking e Robertson (1976), a informação aparece como aquilo que produz diferença, à medida que modifica as estruturas mentais das pessoas. O processo vislumbrado pelos autores é analisado com base na relação entre pessoas e textos escritos (signos intencionalmente estruturados). Neste caso, é possível pensar a produção de diferença mediada por informações e conhecimentos registrados em documentos, tais como livros, capítulos de livros, artigos científicos, trabalhos apresentados em congressos e tantos outros suportes que fazem parte da rotina de ocupação dos estudantes em diferentes níveis de ensino, sobretudo os que frequentam cursos universitários de graduação ou de pós-graduação, a exemplo dos estudantes estrangeiros em tela.

O contato com as teorizações da autonomia das migrações, por sua vez, permitiu pensar os estudantes estrangeiros como migrantes, à medida que Sandro Mezzadra (2005) utiliza o termo migrantecomo um amplo guarda-chuva, a fim de abarcar as experiências de diferentes pessoas que buscam novos possíveis fora do país de origem. Nesta direção, em sua obra Derecho de fuga, esse autor, sustentado nos estudos de Stephen Castles, vislumbra o fenômeno migratório em suas múltiplas motivações, avançando sobre os estudos mainstream que concebem o migrante unicamente como força de trabalho em movimento, e, de modo similar, do refugiado, como aquele que é expulso pelos desastres naturais ou por toda sorte de perseguição. Para além dos fatores objetivos, 0 ato de migrar comporta fatores subjetivos importantes, tais como desejos e aspirações quase sempre negligenciados nas abordagens tradicionais (DE GENOVA; MEZZADRA; PIKLES, 2014). Por conseguinte, ao lado da busca por trabalho e das pressões naturais, políticas, econômicas ou religiosas, Stephen Castles (2000) e Mezzadra $(2005,2012)$ permitem que sejam vislumbradas tambémas motivações orientadas pelo desejo de uma vida afetiva, de diplomação universitária, de viver em um país com um estilo de vida mais compatível, entre outros propósitos. E nas situações mais críticas, como aquelas que afetam os refugiados, têm-se pessoas que migram para lutar pela própria vida e pela liberdade. Com efeito, esses autores alertam para a necessidade de se repensar o conceito de migração e de migrante na contemporaneidade, haja vista que no século XXI eles assumem novas feições e sentidos, diferenciando-se do que foi registrado em momentos históricos anteriores. 
Na produção de Mezzadra (2005), a pessoa migrante é vista, grosso modo, como aquela que sai do país de origem em busca de liberdade. Para ele, a saída é não mera expulsão, mas a decisão de uma pessoa dotada de protagonismo, capaz de produzir um ato político que, nos escritos e nas conferências do autor aparece representado pelo conceito positivado de "fuga". Isto é, a decisão de evasão da nação como um direito, sobretudo quando o país de origem não oferece condições para que as pessoas possam viver e exercer o direito à educação, saúde, segurança, paz, e mesmo o direito à liberdade. Nesta perspectiva, a fuga emerge como a recusa deliberada a uma forma de existência limitante e imobilizante, precariamente assistida (ou desassistida), super explorada e desumana.

Sobre o termo migrante, há que se observar que enquanto a legislação migratória de diferentes países e os organismos multilaterais utilizam terminologias que segregam as pessoas que migram em tipos bem específicos, centrifugando aquelas que merecem acolhimento, proteção legal, comoção social ou mesmo tratamento diplomático diferenciado, Mezzadra (2005) as reúne em uma única categoria. Independente das motivações que as levam a deixar o país de origem, o que interessa ao politólogo italiano é a produção de novas subjetividades processadas nessa experiência, com tudo o que comportam de positivo e negativo.

Deste modo, é no quadro de referência apresentado que os estudantes estrangeiros podem ser vislumbrados como migrantes. Isso porque se o tempo de residência é um critério a ser levando em consideração para definir o migrante, Castles (2000) diz que ele está longe de ser objetivo, pois varia conforme a legislação migratória de cada país, pois:

Migração significa o estabelecimento de residência por um determinado período, mínimo de seis meses, digamos, ou um ano. A maioria dos países tem um número variado de categorias em suas políticas de migração e estatísticas. Por exemplo, a Austrália faz uma distinção entre imigrantes permanentes e imigrantes temporários de longo prazo, que permanecem pelo menos 12 meses, normalmente para trabalho, negócios ou educação (CASTLES, 2000, p. 270).

Em razão disso, é possível referir-se aos estudantes estrangeiros como migrantes temporários, migrantes estudantis, estudantes migrantes ou simplesmente migrantes. Não apenas porque eles estão sujeitos à ritualística documental e processual necessária à obtenção ou à renovação do visto, tal como os demais migrantes ${ }^{1}$, mas, sobretudo, porque entre os colaboradores foram encontrados estudantes que já residem há mais de 
sete anos no Brasil, o que os torna migrantes de fato, ainda que não sejam considerados como de direito.

\section{0 contato com novas informações e conhecimentos produzindo diferença}

Os dados recolhidos junto aos colaboradores revelam as percepções dos estudantes migrantes quanto aos processos de produção de diferença experimentados ao longo da vivência com a sociedade brasileira. Esses processos são entendidos como bastante complexos, emergindo das interações sociais entre estrangeiros e brasileiros, e mesmo entre outros estrangeiros, dentro e fora das universidades, mobilizando informações e conhecimentos. Aliás, o contato com esses intangíveis se realiza sob duas formas. Uma delas corresponde às informações e aos conhecimentos objetivados, isto é, registrados em algum tipo de suporte físico ou digital, estando intimamente associado às atividades que esses jovens têm a cumprir ao longo da formação acadêmica na graduação ou na pósgraduação, bem como nos momentos de lazer em que a leitura recreativa existe como um hábito regular para eles. Outra forma ocorre em uma dimensão subjetiva, quando eles entram em contato com informações e conhecimentos que resultam da produção de sentido sobre o que é visto, sentido e vivido na sociedade de recepção.

Do ponto de vista operacional, há que se dizer que nem sempre é fácil recolher evidências sobre processos de produção de diferença. A principal razão para isso talvez resida no fato de que as pessoas experimentam mudanças não necessariamente de forma consciente. Ademais, a rotina de atividades dessas pessoas mescla estudos, cuidados domésticos, participação em atividades culturais, relacionamentos familiares mediados pelas tecnologias remotas de comunicação e mesmo os raros momentos de ócio, de maneira que a autorreflexão sobre a experiência migrante não constitui prioridade para eles enquanto a vivenciam.

Conforme observa Gusmão (2012), processos de mudança nos estudantes migrantes são percebidos mais comumente quando da realização de viagens à sociedade de origem. Quer nas idas de férias ou mesmo após a diplomação/titulação, o reencontro com familiares e amigos os expõem a julgamentos pelos quais são percebidos como pessoas diferentes, tanto no modo como vestem, quanto na forma como pensam e falam. Neste sentido e considerando os dados recolhidos com estudantes migrantes, as diferenças indicadas foram classificadas com base nas palavras significativas presentes nas falas dessas pessoas, tal como instrui Bardin (2016) quanto ao uso da AC. Dessa análise resultaram quatro classes, a saber: 
a) Diferenças de ordem infocognitiva: correspondem àquelas decorrentes do contato com novas informações e conhecimentos nas cidades brasileiras, dentro e fora dos muros das universidades;

b) Diferenças de ordem comportamental: como o próprio nome sugere, referem-se àquelas percebidas na conduta e nos modos de agir dos estudantes;

c) Diferenças de ordem cultural: dizem respeito às percepções de diferença nos modos de falar, manifestas precisamente por palavras e expressões de uso cotidiano nas interações comunicativas entre brasileiros. Esta classe também representa diferenças ligadas ao contato com as músicas, as danças e a culinária brasileira em suas particularidades regionais;

d) Diferenças não tipificadas: esta última classe reúne respostas pelas quais os estudantes contatados admitem alguma diferença resultante no convívio com a sociedade de recepção, mas não conseguem expressá-la de forma precisa.

Os dados recolhidos mostram que as principais mudanças assinaladas pelos estudantes estrangeiros são de ordem infocognitiva e comportamental. Sobre o comportamento, eles dizem que a experiência de morar fora de casa, longe do controle familiar, permitiu que se tornassem mais "responsáveis", "maduros", "autônomos", e, alguns casos, socialmente mais desenvoltos em relação ao que eram. Os estudantes também percebem que a experiência de estudar e de viver em terras brasileiras acabou por produzir diferenças na forma de pensar e nas imagens pré-concebidas trazidas com eles, à medida que entraram em contato com uma nova realidade, às vezes bastante contrastante com os valores, os códigos morais, as normas sociais e a vivência educacional no país de origem, alterando, deste modo, a bagagem infocognitiva que possuíam na chegada ao Brasil.

Em alguns casos, a partir das interações com compatriotas, com brasileiros e com outros estrangeiros, os estudantes migrantes também mudaram a forma de ver e de pensar o próprio país de origem. Comparando a terra natal ao Brasil, alguns deles se referiram à pátria como sendo bastante conservadora, logo, como um lugar em que não poderiam viver como gostariam, o que remete, por exemplo, à orientação sexual de um estudante latino. Certa vez, durante uma conversa informal pelo WhatsApp em que perguntava sobre os "caminhos" para se chegar à pós-graduação, ele confidenciou sentir-se mais livre para viver o amor e a própria sexualidade na capital São Paulo (SP), muito embora tenha a consciência de que a homofobia também existe no Brasil. Aliás, uma possibilidade de vida sexual e afetiva mais livre para a "comunidade" de gays, lésbicas, bissexuais e pessoas transgêneras que surpreende a um 
estudante de graduação são-tomense (22 anos), originário de um continente que concentra 33 dos 76 países que criminalizam as relações homoafetivas (INTERNATIONAL LESBIAN, GAY, BISEXUAL, TRANS AND INTERSEX ASSOCIATION, 2016).

Entre os colaboradores também foram identificadas mudanças de ordem linguística e cultural. Estas são possíveis pelo convívio com os brasileiros, permitindo que os estudantes assimilem palavras e expressões comuns ao modo de falar nas cidades em que residem e estudam. Pela frequência dessas interações comunicativas ao longo da estadia no Brasil, esses modos de falar que mesclam elementos formais e informais são progressivamente incorporados ao léxico desses jovens. Evidências nesta direção são dadas, por exemplo, em trechos de entrevistas e nas respostas abertas do questionário em que apareceram expressões regionais como "égua" e "caraca"2.

Sobre a experiência vivida na capital paraense, uma estudante de doutorado cabo-verdiana (27 anos) relata: "[...] Aprendi principalmente da diversidade regional, musical e gastronômica do país. Isto é, dos diferentes sotaques e falas regionais ("égua!", por exemplo), do prazer de escutar ritmos como o samba ou o carimbó, do gosto do açaí, do tacacá e da tapioca. Igualmente aprendi sobre o respeito que se tem aqui por religiões como o Santo Daime, a UDV3 e as afrobrasileiras [...]". Em entrevista conduzida na cidade do Rio de Janeiro foi possível observar como uma estudante de mestrado peruana (27 anos) já incorporou a palavra "tipo" ao seu modo de falar. Entre os jovens brasileiros essa palavra é muito utiliza como conector de ideias, ou como um marcador linguístico pelo qual introduzem explicações nas situações de comunicação oral.

Os dados recolhidos entre estudantes originários de países lusófonos como Angola, Cabo Verde e Guiné-Bissau revelam dificuldades quanto o uso do português falado no Brasil. Alguns colaboradores relataram que se sentem hesitosos para falar o que se referem como "o português brasileiro", sobretudo em sala de aula e nas situações que exigem comunicação formal. Essa dificuldade deriva, de acordo com eles, das particularidades que a língua portuguesa assume no Brasil, às vezes diferindo bastante do português nativo que trouxeram com eles, reconhecido como mais próximo ao português lusitano. Curiosamente, estudantes de países falantes do espanhol não mencionaram esse tipo de dificuldade. Uma estudante de doutorado boliviana (35 anos) e outra venezuelana (34 anos) inclusive disseram ter escolhido as universidades brasileiras pelo fator idiomático, considerando a língua portuguesa relativamente fácil de ler, escrever e falar.

Pelo convívio e pelas relações sociais construídas no Brasil, os estudantes migrantes falam também de novos hábitos alimentares, de 
outros modos de dançar e de outra maneira de se relacionar com as pessoas, a qual é percebida por eles como mais alegre, afetuosa e menos formal. Esses elementos são vistos pelos estrangeiros como expressões positivas de "brasilidade", isto é, de um jeito de ser, sentir e de viver que, para eles, representa uma característica comum aos brasileiros.

Durante a estadia nas cidades brasileiras, os estudantes contatados podem - ou puderam - conhecer os traços de uma cultura que se particulariza, conforme a cidade ou a região que escolheram para residir e estudar. Lugares com diferentes ritmos musicais que são cantados e dançados pela população local. É com base nesse olhar estrangeiro sobre - Brasil, rico em informações e conhecimentos produzidos por quem vivencia ou vivenciou intimamente a cultura brasileira que, a seguir, se compartilha alguns fragmentos discursivos quanto ao que os estudantes aprenderam nesse convívio:

Mestranda argentina (42 anos): "[...] Aprendi e aprendo muito no meu contato com os brasileiros. Na vida cotidiana, na alimentação, novos sabores, na língua, na cultura e na diversidade, na alegria, entre outros $[\ldots]^{\prime \prime}$;

Mestranda costarriquenha (25 anos): "[...] O idioma e a convivência que brasileiros têm pra acolher gente estrangeira. Sempre convidam a aniversários e festas cotidianas pra que a gente fique à vontade. Sempre são muito atenciosos $[\ldots]$ ";

Doutoranda venezuelana (34 anos): "[...] Principalmente aprendi uma língua. O português hoje é a minha segunda língua. Brasil é um país que em cada canto impressiona. Muito rico culturalmente. É impressionante! $[\ldots]^{\prime \prime}$;

Doutoranda colombiana (35 anos): "[...] Hábitos alimentares. Adicionei à minha dieta o feijão, a farinha e aprendi receitas de escondidinho, caldo verde, entre outras. A ideia das relações sociais e a amizade, apesar de muito diferente da Colômbia, inclui uma postura mais positiva e mais generosa $[. . .]^{\prime \prime}$;

Graduanda francesa (22 anos): "[...] Aprendia todo dia alguma coisa: palavras, gírias, músicas, comida [...]. Aprendi (e continuei a aprender) a ter mais paciência, a comunicar com uma língua diferente, a ser mais compreensiva, a aceitar de não entender tudo, a não ter preconceitos de outras pessoas, a aceitar as diferenças [...]. E ainda muitas outras coisas $[\ldots]^{\prime \prime}$;

Mestranda peruana (27 anos): "[...] Eu aprendi muito sobre sua cultura, quais são os tipos de comida, seu foldore, suas danças, suas festas e o jeito deles de se relacionar no cotidiano. No âmbito acadêmico, aprendi que não há escalas hierárquicas entre alunos e professores. Aprendi que toda pergunta é bem-vinda e ninguém vai me julgar por fazêla $[. . .]^{\prime \prime}$; 
Doutoranda uruguaia (35 anos): "[...] Eu me acostumei a comer produtos tais como tapioca, manga e feijão [...]. Talvez eu também aprendi a ser mais tolerante e despreocupada [...]" e;

Graduando colombiano (32 anos): "[...] Hábitos, ideias, valores... sou uma pessoa de mente mais aberta. Eu era mais conservador [...]".

Os fragmentos discursivos apresentados e outros dados recolhidos sugerem a produção de diferença entre os estudantes migrantes. Por certo, o tempo vivido no Brasil e o contato contínuo ao longo dos anos com a sociedade brasileira foram capazes de afetá-los no modo como pensam sobre si mesmos, em especial sobre quem são ou dizem ser durante ou após o tempo de estadia na "terra do outro"4: flexíveis; tolerantes; amistosos; despreocupados; informais etc. Por ocasião das relações diárias tecidas com os brasileiros, alguns estudantes dizem ter aprendido a "aceitar as diferenças", "respeitar as diferenças", "não ter preconceitos de outras pessoas", "ser mais tolerante", a ser "uma pessoa de mente mais aberta".

Ainda assim, parte dos colaboradores também reconhece o caráter ambíguo da sociedade brasileira, especificamente em seu modo de acolher e de recusar o outro, tal como observa uma doutoranda venezuelana (34 anos): "[O Brasil] é o país das contradições, muita riqueza em recursos, mas, ao mesmo tempo, muita desigualdade, preconceito e racismo, e xenofobia. Isso é muito forte aqui! [...]". Na mesma direção, tem-se o discurso de uma graduanda beninense (25 anos): "Aprendi que o povo brasileiro é simpático, carinhoso e muito animado, mas, é muito hipócrita também". Assim, se esses estudantes migraram para estudar com farto repertório de representações positivas sobre o Brasil, no retorno ao país de origem - ou mesmo na migração para outros destinos internacionais eles levam consigo informações e conhecimentos sobre uma faceta negativa que a sociedade brasileira resiste em aceitar: a que discrimina tanto os de dentro (insiders) quanto os de fora (outsiders), quer sejam mulheres, negros, pobres, homossexuais, migrantes, praticantes de religiões não cristãs e/ou outros.

Mesmo que os estudantes percebam em si traços de personalidade ou de comportamentos que associam aos brasileiros, isto não significa dizer que essas pessoas tenham se "abrasileirado". Eles tão somente se tornaram diferentes do que eram, mais próximos ao modo como nos representam, ou da forma como nos traduzem com base nas informações e nos conhecimentos que adquiriram pelas relações cotidianas com a sociedade local. É possível dizer também que esses jovens se apropriam desses traços apenas temporariamente enquanto vivem no Brasil, a fim de se relacionarem melhor com os locais, e, por ocasião do retorno à pátria, pouco a pouco podem abandoná-los à medida que retomam o convívio com seus familiares, compatriotas, com sua cultura. 
Diante do que foi exposto, os estudantes de origem africana, latino americana e europeia identificam e selecionam características, atitudes e comportamentos positivos do que interpretam como expressões de "brasilidade". Percebidos como úteis, quer dizer, com potencial para torná-los pessoas diferentes, eles dizem que pretendem incorporar esses traços aos seus modos de ser e de viver. Assim, ao analisar os dados e as informações recolhidas, verifica-se que as características observadas pelos estudantes estrangeiros traduzem os brasileiros como pessoas sociáveis, hospitaleiras, afetuosas, espontâneas, otimistas, tolerantes, alegres, despreocupadas com a vida, criativas, generosas, simpáticas e pacientes, entre outros traços. Algumas das pessoas contatadas até declaram ter incorporado parte desses traços, tal como foi informado por uma estudante de mestrado peruana (27 anos). Conforme conta, após estranhar a frequência do contato físico entre os brasileiros, algo incomum no Peru, a estudante já se percebe trocando abraços espontâneos com as pessoas que encontra em suas andanças pelo Rio de Janeiro.

Ainda que as migrações para estudo suscitem a ideia de uma experiência migratória mais "tranquila" se comparada a dos demais migrantes, sobretudo em função do status desses jovens na sociedade de recepção, elas também envolvem dificuldades diversas e não menos sentidas do ponto de vista emocional. É neste sentido que os colaboradores falam das incertezas e dos obstáculos enfrentados ao longo do projeto migratório, em especial pelo elevado custo de vida nas cidades brasileiras em que residem, pelas dificuldades linguísticas e pelo desafio de construir uma nova rede de apoio. Pesquisas como a de Silva e Morais (2012), Ngomane (2015), Daniel (2016), Sousa (2016) e Lima (2017) revelam outras dificuldade, tais como o racismo e a xenofobia dentro e fora do ambiente acadêmico, a insuficiência de recursos financeiros e as barreiras no acesso à informação, especialmente em relação às universidades e aos cursos em que pretendem se diplomar/titular.

Contudo, em que pesem as dificuldades que atravessam a experiência dos estudantes migrantes contatados, o fato que é que eles se mostram confiantes em seus projetos acadêmicos. Três estudantes de doutorado se titularam durante a fase de recolha dos dados, declarandose bastante satisfeitas com os cursos que frequentaram, com as teses que produziram e com a vivência nas cidades em que residiram. Enquanto uma delas retornou a Guiné-Bissau e outra migrou para Madri para contrair matrimônio, outra segue tentando a carreira docente no estado do Pará. Muito embora uma doutoranda de origem italiana (41 anos) tenha sido a única a se mostrar descontente com os brasileiros, com os estudos e com a vida no Rio de Janeiro, 34 pessoas avaliam como bastante positiva a decisão de estudar e de viver nas cidades brasileiras. É neste sentido que as experiências desses jovens se aproximam da epopeia 
de Ulisses, o herói mítico que teve os anos de ausência e de dificuldades recompensados com o retorno ao seio familiar. Para os estudantes migrantes, o tempo vivido longe da terra natal talvez possa ser compensado pelo reconfortante acolhimento familiar e pela inserção no mercado de trabalho ao final de uma jornada pela diplomação/titulação.

\section{Considerações finais}

Neste trabalho viu-se que a experiência de estudar e de viver no Brasil leva os estudantes estrangeiros a se perceberem como pessoas diferentes pelo contato com a sociedade de recepção.Mais do que o contato com o conhecimento explícito acessado nas universidades brasileiras, os estudantes entraram em contato com outras formas de conhecimento. Este pode ser considerado de ordem prática e se funda em um aprendizado orientado para a vida. Em potência, esse conhecimento informal (tácito) será levado com esses jovens no retorno ao país de origem ou mesmo para outros destinos internacionais, independentemente de serem utilizados no futuro, ou não. É possível falar, então, do resultado do encontro com uma nova sociedade e cultura, capaz de alterar as subjetividades desses estudantes pelas experiências positivas e negativas vividas na "terra do outro".

Por fim, considera-se que esses jovens estão em contato íntimo, contínuo e intenso com a sociedade de acolhida, experimentando a cultura, os valores, as crenças, os costumes e as normas sociais que orientam a vida das pessoas no Brasil. Um contato suficientemente significativo para desencadear algum tipo de mudança nas identidades e nas subjetividades desses estudantes, muito além do que uma simples viagem pode produzir no turista internacional em sua breve estadia. Ademais, a passagem da condição de estudante a migrante de direito depende do grau de identificação com o país de acolhida, bem como das perspectivas que se abrem para os estudantes. Deste modo, permanecer no Brasil está para o horizonte de possibilidades desses jovens tanto quanto a esperança do retorno à pátria está para os demais migrantes. $\mathrm{E}$ seja como for ou para onde quer que (re)migrem, os jovens aqui contatados estão pondo em marcha um processo de circulação de informação e conhecimento de natureza científica e prática. Isto ocorreem um ato seletivo, por meio do qual decidem o que de mais útil a experiencia de viver e de estudar no Brasil produziu em suas subjetividades, precisamente pelos novos intangíveis a que tiveram acesso nas universidades, e, de forma mais ampla, pelas pessoas com as quais interagiram na sociedade de recepção.

\section{Notas}


${ }^{1}$ No Brasil épermitido que estudantes estrangeiros trabalhem, tal como determina a Resolução Normativa n. 124/2016, do Conselho Nacional de Imigração (BRASIL, 2016).

${ }^{2}$ Interjeição de uso comum no falar dos paraenses que, dependendo da entonação - como o "caraca", dos cariocas -, pode expressar muitos estados emocionais, tais como alegria, surpresa, aborrecimento, frustração e outros.

3 Forma como a estudante designa o Centro Espírita Beneficente União do Vegetal, conhecido, entre outras coisas, pelo uso do chá ayahuasca nas vivências espirituais dos seus membros.

${ }^{4}$ Expressão tomada de empréstimo de Gomes (2002).

\section{Referências}

ANDERSON, Benedict. Comunidades imaginadas:reflexões sobre a origem e a difusão do nacionalismo. São Paulo:Companhia das Letras, 2008.

BARDIN, Laurance. Análise de conteúdo. São Paulo: Edições 70, 2016.

BATESON, Gregory.Steps to an ecology of mind. Chicago: The University of Chicago Press, 2000.

BELKING, Nicholas J.; ROBERTSON, Stephen E. Information Science and the phenomenon of information. Journal of the American Society for Information Science.[S.I.], v. 27, n. 4, p. 197-204, Jul./Aug. 1976.

BRANDÃO, Junito de Souza. Mitologia grega: volume 1. Petrópolis: Vozes, 2015.

BRASIL. Ministério do Trabalho. Conselho Nacional de Imigração.

Resolução Normativa n. 124, de 13 de dezembro de 2016. Dispõe sobre a transformação da condição migratória temporária de estudante para a condição migratória temporária de trabalho. Diário Oficial [da] República Federativa do Brasil, Seção: 1. Edição: 245. Brasília, DF,13 dez., p. 179, 2016.

CASTLES, Stephen. International migration at the beginning of the twenty-first century: global trends and issues. International Social Science Journal.[S.I.], v. 52, n. 165, p. 269-281. 2000. Disponível em: http://onlinelibrary. wiley.com/doi/10.1111/14682451.00258/pdf. Acessoem: 10 dez. 2017.

DANIEL, Camila. Mobilidade estudantil internacional como uma experiência migratória: o caso dos estudantes peruanos no Rio de Janeiro. In: PÒVOA NETO, Helion; SANTOS, Miriam de Oliveira; PETRUS, Regina (org.). Migrações: rumos, tendências e desafios. Rio de Janeiro: PoloBooks, 2016. p. 305-328. 
DE GENOVA, Nicholas; MEZZADRA, Sandro; PIKLES, John. New keywords: migration and borders. Cultural studies. [S.I.] v. 29, n. 1, p. 55-87, 2014.

GOMES, José Manoel Sita. Estudantes na terra dos outros: a experiência dos universitários angolanos da Universidade Federal de Minas Gerais Brasil. (Mestrado) - Faculdade de Educação, Universidade Federal de Minas Gerais, Belo Horizonte, 2002. Disponível em:

www.bdae.org.br/dspace/bitstream/123456789/2120/1/tese.pdf. Acesso em: 15 out. 2017.

GUSMÃO, Neusa Maria Mendes de. África, Portugal e Brasil: um novo triângulo das Bermudas? Cadernos CERU. [S.I.], v. 23, n. 2, p. 51-62, 2012. Disponível em:

http://www.revistas.usp.br/ceru/article/view/56877. Acesso em: 22 set. 2017.

INTERNATIONAL LESBIAN, GAY, BISEXUAL, TRANS AND INTERSEX ASSOCIATION. Homofobia de Estado. Genebra: ILGA, 2016. Disponível em:http://ilga.org/downloads/02 ILGA Homofobia De Estado 2016 ESP WEB 150516.pdf. Acesso em: 28 set. 2017.

LIMA, Renata de.Analisando as motivações dos estudantes estrangeiros do Instituto Oswaldo Cruz na Função Oswaldo Cruz. Dissertação(Mestrado) Fundação Oswaldo Cruz, Instituto Oswaldo Cruz, Rio de Janeiro, 2017.

MEZZADRA, Sandro. Capitalismo, migraciones y luchas sociales: apuntes preliminares para una teoría de la autonomía de las migraciones. In: MEZZADRA, Sandro. Derecho de fuga: migraciones, ciudadania y globalización. Madrid: Traficantes de Sueños, 2005. p. 143-157.

Disponível em:

http://www.traficantes.net/sites/default/files/pdfs/Derecho\%20de\%20fug a-TdS.pdf. Acesso em: 4 dez. 2017.

MEZZADRA, Sandro.Multidões e migrações: a autonomia dos migrantes.ECO-PÓS: Revista do Programa de Pós-Graduação da Escola de Comunicação da UFRJ. [Rio de Janeiro]v. 15, n. 2, p. 70-107. 2012. Disponível em:https://revistas.ufrj.br/index.php/eco pos/article/view/900. Acesso em: 28 ago. 2017.

NGOMANE, Yara. A fabricação do parentesco entre estudantes moçambicanos. In: MACHADO, Igor José de Renó(org.). Deslocamentos e parentesco. São Carlos: Ed UFSCar, 2015. p. 145-166.

REZENDE, Claudia Barcellos.Retratos do estrangeiro:identidade brasileira, subjetividade e emoção. Rio de Janeiro: FGV, 2009. 
SILVA, Kelly; MORAIS, Sara Santos. Tendências e tensões de sociabilidade de estudantes dos Palop em duas universidades brasileiras. Pro-Posições. [S.I.],v. 23, n. 1, p. 163-182, 2012. Disponível em:

http://www.scielo.br/pdf/pp/v23n1/11.pdf.Acesso em: 22 set. 2017.

SIMMEL, Georg. A metrópole e a vida mental. In: VELHO, OtávioGuilherme (org.). O fenômeno urbano. 2. ed. Rio de Janeiro: ZaharEditores, 1973. p. 11-25. (Textos básicos de Ciências Sociais).

SOUSA, Isabela Cabral Félix de. Deslocamentos na socialização de estudantes estrangeiros em instituições acadêmicas voltadas para a saúde no Rio de Janeiro. In: PÒVOA NETO, Helion; SANTOS, Miriam de Oliveira; PETRUS, Regina (org.). Migrações: rumos, tendências e desafios. Rio de Janeiro: PoloBooks, 2016. p. 329-346. 